MATEC Web of Conferences 52, 03004 (2016)

DOI: $10.1051 /$ matecconf/2016520300 4

(C) Owned by the authors, published by EDP Sciences, 2016

\title{
Modern Landscape Representation of Hakka Culture
}

\author{
Huang Hui ${ }^{1, a}$, Gao Ruofei ${ }^{2}$ \\ ${ }^{1}$ Landscape Design Department, Shenzhen Polytechnic, Shenzhen, China \\ 2 Doctor of Chiba University, Japan
}

\begin{abstract}
Hakka culture is a combination of ancient Chinese culture, aboriginal southern culture and hilly environment, whose influence spreads more than 80 countries and regions in the world. It is more difficult to summarize the regional landscape representation techniques of Hakka culture under the background of modern landscape. The author makes a comparative study of landscape representation techniques of the three typical Hakka landscapes, putting forward modern landscape ideas of Hakka culture in order to provide reference for construction of other regional landscapes.
\end{abstract}

\section{Introduction}

Hakka culture is not only diverse but also unique [1]. Hakka people is a special department that was ultimately formed after several ethnic migrations, which is one of the Han nationality branches with many characteristics of southern ethnics at the settlement surroundings, retaining the relative integrity of the central plains culture. Meanwhile, it is a diverse and unique cultural system that was ultimately formed after the interaction and permeability with the local culture of Baiyue and Yaoshe.

Hakka traditional architecture, especially Hakka Round House, is one of the important carriers and symbols of Hakka culture, which is known as "the world's unique mythological mountain building model [2]". The research, resulting from the study of many Hakka traditional architecture [3] [4] [5] [6] [7], is helpful to summarize the basic connotation and typical characteristics of Hakka culture.

In the modern landscape design, how to inherit local culture better so that the design works are of more regionalism, melting into regional environment, and how to maintain a more long-term vitality, are the ongoing topics of the modern landscape design practice [8] [9] [10]. "World Hakka city" in Meizhou City, Guangdong Province continues to build the three large Hakka scenic areas: Yannanfei tea garden, Ketianxia Tourism Park and Ruishan mountain hi-tech eco-agricultural park. While comparatively studying the landscape representation techniques of the three main Hakka scenic areas, this paper aims to summarize the Hakka culture, trying to put forward the basic concept of modern Hakka landscape design so as to provide reference for the regional landscape design.

\section{The Hakka culture}

\subsection{Hakka culture and its typical characteristics}

a Author : huanghui72@szpt.edu.cn

This is an Open Access article distributed under the terms of the Creative Commons Attribution License 4.0, which permits unrestricted use, distribution, and reproduction in any medium, provided the original work is properly cited. 
Hakka culture springs from the Confucian culture at the year 0 to A.D. 1000, which has developed during five migrations to the South at the year A.D. 1000 to A.D.2000. Mr. Ge Jianxiong said: "Since the purpose of migration is to settle down, people have to make a choice in culture. They can accept the culture which they migrate to so that they can melt into it; or they have to adhere to their own culture so as to carry it out among the local people." However, the Hakka people in the history adhere to the Confucian culture during the migrations, while they gradually integrate into cultures from place to place, which is a kind of derivative culture under the influence or the choice of the natural environment and human environment. Subsequently, due to the relocation to Nanyang ${ }^{*}$, Hakka culture becomes a model of integration of Chinese culture and world culture.

Nanyang:a general name used towards the end of the Qing Dynasty for the coastal provinces of Jiangsu, Zhejiang, Fujian and Guangdong; an old name for the Malay Archipelago, the Malay Peninsula and Indonesia or for southeast Asia.

\subsection{Hakka culture and Hakka traditional resident community}

Hakka Round House is an important carrier of Hakka culture. The building community which is harmony with mountains, the magnificent and simple style, bright and plain color, natural ecological environment and introverted inspirational decoration make it unique among the traditional local dwelling houses.

Hakka Round House faces water with hills on the back, whose terrain falls off the land from high to low in turn: $\mathrm{Zu}$ Shan Mountains, Feng Shui landscape forest, the settlement architecture, Wo Ping, Moon pond (Feng Shui pond shaped as half-moon), fields and streams. Ecological base of traditional Hakka residential community is composed of the mountain hills, rivers and streams and plant community. The round house patches, isolated from each other by the terrain, are connected by streets and water body. Such special ecological structure melts the natural elements into the living community, which is a model of the organic combination of the living community and natural environment.

\section{Modern representative Hakka landscape}

\subsection{Three modern Hakka landscape cases}

Meizhou City in Guangdong Province, known as the "World Hakka city", is the main ancestral home of overseas Chinese Hakka. Yannanfei tea garden, Ketianxia Tourism Park and the Ruishan mountain hi-tech eco-agricultural park are three relatively large Hakka theme parks that have been newly built at Meizhou in recent years.

The Yannanfei tea garden (Figure 1) is one of the national AAAA level scenic spots, which is a set of Hakka tea culture and tourism with an excellent eco-environment. Based on the superior natural eco-resources and tea fields with standardized production, scenic areas show a broad and profound tea culture. The landscape and architecture in scenic areas, such as thick and Green Tea Park, water,

Villa, Round-Dragon Hotel and Round-Dragon Restaurant, work in concert with the traditional Hakka residential community.

Ketianxia tourism park (Figure 1) was built among the natural mountains with original ecology and the three major reservoirs. By digging deeply in Hakka culture, the park is set up ten major cultural projects and the five major scenic areas, changing "culture pulse" into "landscape pulse" throughout the park, which is an epitome of a combination of history and modern, culture and leisure at Meizhou City.

Ruishan mountain hi-tech eco-agricultural park (Figure 1), taking ecology and health as the theme, is a beautiful place with overlapping peaks and metasilicic acid underground water source which is beneficial to the human body. Being harmony with the mountains, three hotel constructions whose configuration takes Hakkas Round-Dragon house as a reference, constitute a shape of Ruyi with three 
oval buildings (service center, restaurants and office buildings), which symbols good fortune and longevity.



Figure 1 Master plan for Yannanfei tea garden, Ketianxia tourism park and the Ruishan mountain hi-tech ecoagricultural park

\subsection{Typical landscape representation techniques}

Contemporary landscape designers think that the landscape is a text that can be read and understood, whose major component is the landscape symbol. By selecting landscape symbols, and reorganizing codes and structures, combined with the hints, associations, memories and other techniques, landscape design closely links these obvious or ambiguous symbols and metaphors with history and society, arranging cultural information in it, so as to make people have an assocation that proceeds from one to another so that people can understand things that can not be seen, achieving emotional resonance. From the perspective of the formation of the symbols and structures, there are two following types of refinement of the traditional landscape symbols: general type and restructuring type. General landscape symbol, often originating in people's common cognitives, generally is conventional image and meaning with the characteristics of commonality and universality. The restructuring landscape symbol is a new kind of symbol structures, which is formed by restructuring the materials, patterns or structures of traditional landscape symbols. Being closely connected with traditional culture, the restructuring landscape symbol keeps a tentative relationships with traditional so as to produce the symbol and metaphor for traditional culture.

After field-exploring in three Hakka scenic areas, collecting and reorganizing materials, the author summarizes typical landscape representation techniques as follows (Figure 2): 


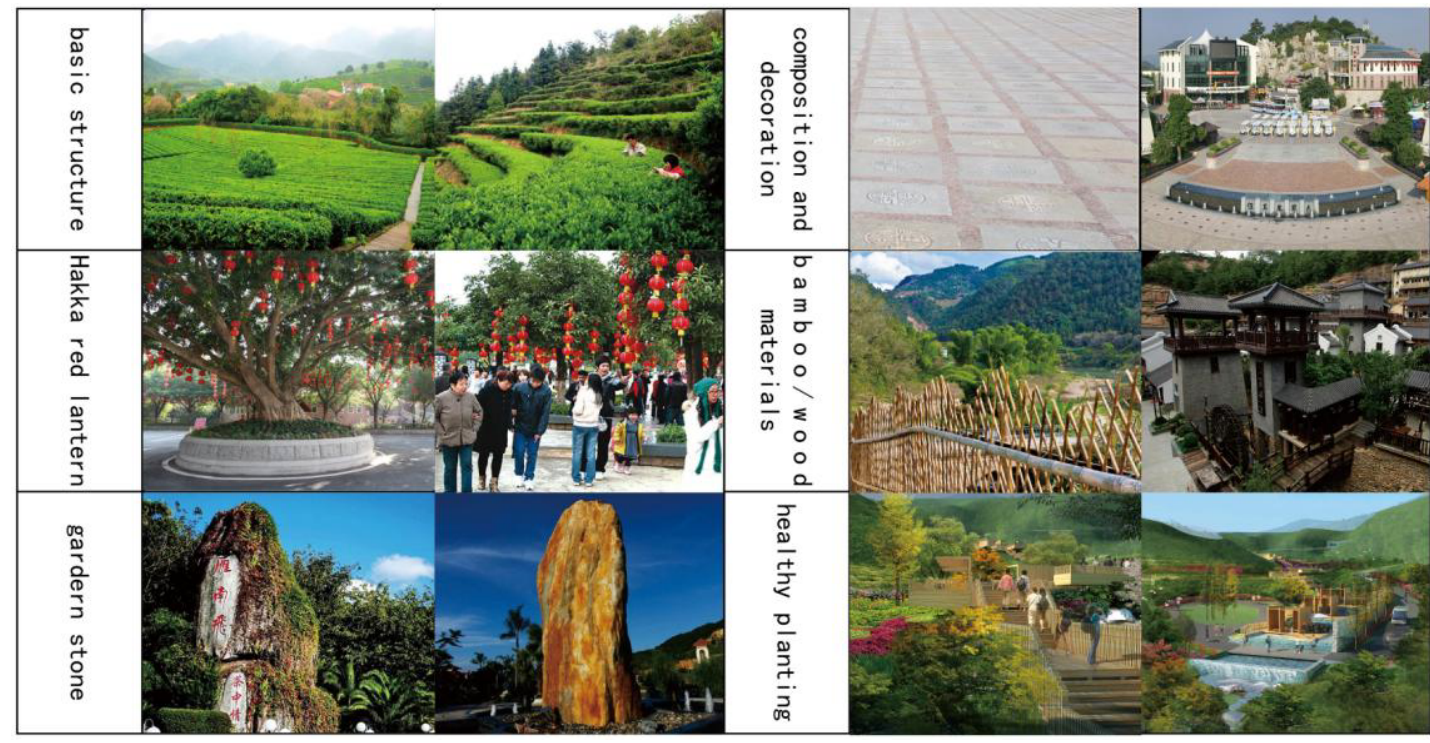

Figure 2 The basic structure of Feng Shui forest, terraces and streams

Being similar with the patterns of traditional Hakka residential community, the basic structure of the three Hakka scenic areas retain the Feng Shui forest, terraces and streams and other elements. Being different from the proportion of buildings and land in the traditional Hakka settlements, Yannanfei tea garden whose main purpose serves for production focuses on the terrace with structures such as hotels, villas and teaculture buildings as an embellishment. While cultivating the Feng Shui forest, the hotel and the valley streams in the Ruishan Mountain hi-tech eco-agricultural park, the terrace is replaced by the healthy plant in order to strengthen the health function of the park. These general landscape symbols and the landscape structures that are composed of those make it very easy for people to have an association with the traditional Hakka settlements.

1) Round and curved composition and decorations

Drawn from Hakka representative round house, many modern Hakka buildings have the characteristics of resistance of the chill of the valley, enlargement of the utilization area and reduction of sunshine corner, etc., which are more suitable residential patterns for hotels. In addition to hotels, the landscape architecture and decorative patterns are more likely to be circular or arcuate so as to echo the architectural forms. For instance, a large number of circular paving patterns echo to the form of hotel architecture in Yannanfei tea garden. In addition, round Central Square in Ruishan mountain hi-tech eco-agriculture garden is a kind of hints and metaphors of Hakka culture. The decoration and composition of these landscapes are the symbols and metaphors of Hakka culture by restructuring landscape elements.

2) Hakka characteristic red lantern

In the Hakka areas, red lantern is the continuation of the central plains culture, symbolizing family reunion, prosperity, happiness, brightness, vitality, perfection and wealth. In Yannanfei tea garden and Ketianxia Tourism Park, a large number of red lanterns not only highlight the Hakka characteristics and unique artistic style, but also supplement lighting in scenic spots. Red lanterns, as a common type of landscape symbols, strengthen the Hakka atmosphere in the scenic areas.

3) Concerted tradition of bamboo/wood materials

Hakka traditional architecture utilizes a large number of natural materials, such as bamboo, wood, red clay and stone, etc., while modern Hakka architecture uses much more artificial materials to meet the need of shaping and cost control. Nevertheless, these landscape architecture that is made of natural materials becomes the echo of modern Hakka landscape, nature and tradition. Thus, the reorganization of these materials can faintly reflect the silhouette of the traditional Hakka culture.

4) Regional specialty garden stone and stonework 
Hakka traditional settlements are maily located in the hilly region which is more than $50 \%$ of Meizhou city. The special geological structure is teem with garden stone, granite and other kind of stone. The foundation of traditional Hakka building utilizes a large number of local stone. There are themic displays of garden stone in the three parks, such as the Yannanfei flying god rock in Yannanfei tea garden, King Stone in Ketianxia Tourism Park and many characteristic landscape stone among hiking trails in Ruishan mountain hi-tech eco-agricultural park. The local stone is also used at Hakka town in Ketianxia Tourism Park, the round square at entrance Stage one in Ruishan mountain hi-tech eco-agricultural park and lake landscape.

5) Healthy planting

A large number of healthy planting used at Ruixiang Valley in the Ruishan mountain hi-tech ecoagriculture park suit the theme of health and ecology. Under the background that health problems have gradually integrated into policies in many countries, more applications of healthy planting in landscape design are needed to meet the demand of the social development in China, especially in South China, which mathces the typical characteristics of Hakka culture that is eclectic, pioneering and enterprising, promoting the existence and development of the group and individuals of Hakka people. The first application of healthy planting in Hakka landscape is not only one of the attempts to apply the health problems in the landscape, but also landscape practitioners judgment of the development direction of the modern landscape under the influence of Hakka culture.

\section{Conclusion}

Hakka culture, especially its characteristics and spirit of being pioneering and enterprising, is a key factor in the continuation and longevity of the Hakka people's system. Under the guidance and influence of Hakka culture and its typical characteristics, combined with the existing typical landscape representation techniques, Hakka modern landscape shows a somewhat characteristics of the regional landscape. However, taking healthy landscape as the developmental goal and the main function will offer the Hakka modern landscape a more permanent life, which the author hopes that it can become regional characteristic landscape representative that guides one kind of modern landscape development direction.

\section{References}

1. Hagel, translated by Wang Zaoshi, Historical Philosophy, Shanghai Century Publishing Group, Shanghai Bookstore Press, 2001

2. Luo Jianhe, Cao Zhibo, "the inspiration of the form of traditional folk residence architecture and cultural spirit to modern logo design", "Guangdong education· Vocational Education", 2012

3. Xiong Jinhui, "the impact and influence of Hakka culture on contemporary design", "Journal of Jiangnan University", 2008

4. Luo Jianzi. "The inspiration of Hakka traditional architecture to modern architecture design - the design of Hakka world museum ", South China University of Technology Press, 1997

5. Wu Xichao finishing, " The abstract of thesis of Hakka spirit", the Chinese cities and counties network, 2008-07-31

http://www.21ccct.com/sh/2008/0731/article_65.html

6. Cai Hong, "The perception of inheriting national culture and exploring Hakka architecture mystery -- on the new trend of architectural culture in Meizhou city"

7. http://www.kslaw.com.cn/paperview.asp?papert=article\&id=4011, 2012-6-18

8. Li Junjie, "the protection and inheritance of the Hakka culture of world heritage landscape in Yongding Storied Buildings". Fujian Agriculture And Forestry University, 2013

9. Passengers City Network http://www.mz186.com

10. The website of Hi-tech industry garden at Meizhou, Guangdong http://www.gdmzgxq.gov.cn

11. Health News Network http://www.jkb.com.cn 